\title{
Structural alterations of extraocular muscle associated with Apert's syndrome
}

\author{
SHEILA MARGOLIS, BRUCE R. PACHTER, AND GOODWIN M. BREININ \\ From the Department of Ophthalmology, New York University Medical Center, New York
}

SUMMARY An inferior oblique muscle from a patient with Apert's syndrome was examined by light and electron microscopy. Alterations in the muscle fibres, the myoneural junctions, and intramuscular nerves were observed. These data are not compatible with the widespread notion that motility disturbances in this syndrome are solely due to mechanical limitations.

Apert's disease, or acrocephalosyndactyly (Apert, 1906), consists of oxycephaly (tower skull), exophthalmos, strabismus, antimongoloid fissures, maxillary hypoplasia, optic atrophy, and syndactyly (fusion of fingers 2 to 4 ). Ocular motility disturbances occur frequently in Apert's disease. It has been reported that at least 45 to $78 \%$ of patients seen with Apert's and Crouzon's diseases, both craniofacial dysostosis, have strabismus (Davis, 1925; Laitinen et al., 1956). Overacting inferior oblique muscles and slight underaction of superior oblique muscles occurred frequently, It has been suggested (Lloyd, 1975; Miller and Folk, 1975) that these motility anomalies result from mechanical limitations of the globe which are secondary to the bony malformation of the orbit. In the present investigation, the first to directly examine the structure of extraocular muscle associated with Apert's syndrome, light and electron microscopic evidence is indicative of morphological abnormality.

\section{Case report}

The patient was a 13-year-old girl who had oxycephaly resulting from complete closure of the coronal sutures, shallow orbits, bilateral exophthalmos (Fig. 1), and syndactyly of the hands (Fig. 2) and feet. Consequently, she had a craniotomy to open the coronal sutures, and a follow-up examination showed normal motor progression, and good preservation of vision, with normal speech and intelligence. Over the years various surgical procedures had been performed to correct the physical deformities typical of Apert's syndrome - cleft palate, bifid uvula, and fusion of fingers.

Requests for reprints to: Dr Bruce R. Pachter, Department of Ophthalmology, New York University Medical Center, 550 First Avenue, New York, New York 10016, USA
OCULAR EXAMINATION

Cycloplegic refraction of the OD was +2.00 $-0.25 \times 90$ and $O S+2.25$ sphere with visual acuity OD $20 / 40$ and OS $20 / 30$. Two years later examination showed a corrected vision of $20 / 25 \mathrm{OU}$. The patient had antimongoloid fissures with shallow orbits and prominent globes which measured at base 110 by exophthalmometer OD $20 \mathrm{~mm}$ and OS $19 \mathrm{~mm}$. Further examination showed an interpupillary distance of $70.5 \mathrm{~mm}$ with an intercanthal distance of $39 \mathrm{~mm}$. No nystagmus was evident. The

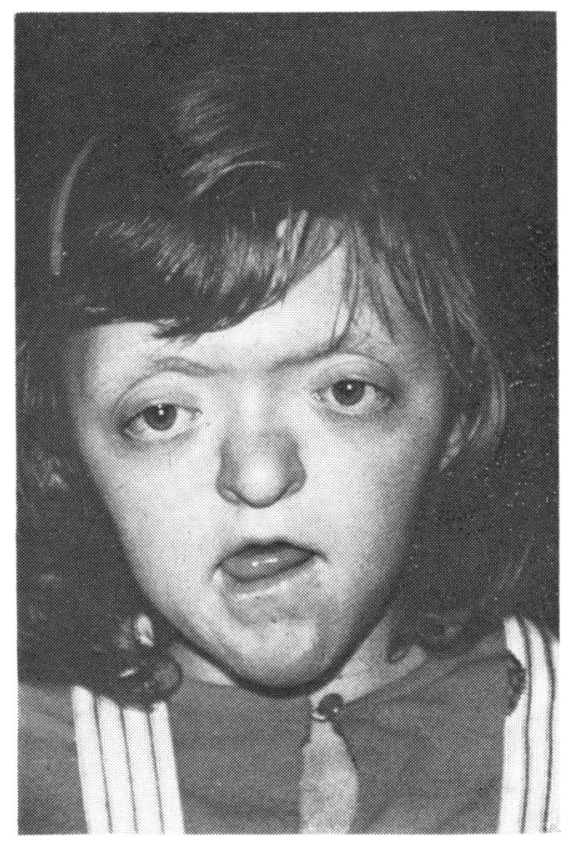

Fig. 1 Patient with Apert's syndrome showing antimongoloid fissures, exophthalmos, and hypertelorism 


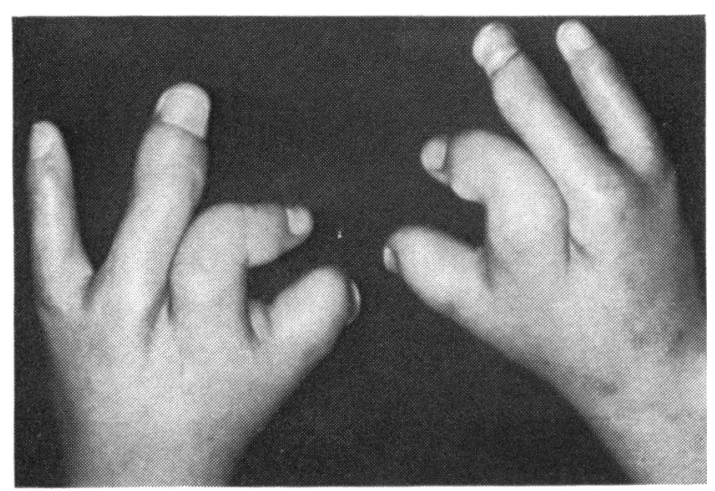

Fig. 2 Syndactyly of fingers

NPC was $40 \mathrm{~mm}$. The anterior segment was unremarkable except for bilateral transillumination of the iris base. In addition it was noted in both eyes that the lens and vitreous were normal. Except for a suggestion of pallor of the right disc temporally, the optic nerves and blood vessels were normal. There were good foveal reflexes in both eyes, with decrease in the retinal pigmentation, which allowed for increased visibility of the underlying choroidal vessels anterior to the equator in the superior temporal and inferior nasal quadrants.

A ' $V$ ' pattern esotropia was present. On upward gaze there was an ET 25, RHT 14, and on downward gaze an ET 40, RHT 14 for distance and near. The patient had bilateral elevation in adduction, with overacting inferior obliques $\mathrm{OU}$ and underacting superior obliques OU. There was also decreased abduction OU with $3 \mathrm{~mm}$ of bared sclera. Sensory evaluation showed alternating suppression. Surgery for correction of strabismus was performed, which was $4 \mathrm{~mm}$ recession of left medial rectus, $8 \mathrm{~mm}$ recession of left lateral rectus, as well as bilateral inferior oblique disinsertions.

Laboratory tests: ERG, EOG, serum tyrosine, and phenylalanine levels and chromosome studies were all normal.

\section{Materials and methods}

The right inferior oblique was completely disinserted, and a segment of approximately $8 \mathrm{~mm}$ was taken from its belly portion and initially fixed in $1 \%$ paraformaldehyde $/ 1 \%$ glutaraldehyde in phosphate buffer for 4 hours, then transferred to $4 \%$ glutaraldehyde overnight. The muscle segment was postfixed in $1 \%$ osmium tetroxide, dehydrated in graded alcohols, and embedded whole in Epon 812. The embedded muscle segment was serially sectioned at $15 \mu \mathrm{m}$ by steel knife on a sliding microtome. These thick sections were cleared for light micro- scopy by curing a layer of Epon on to them within a sandwich of polystyrene film (Davidowitz et al., 1976). The complete muscle biopsy could thus be initially surveyed by phase contrast for the detection of disrupted fibres and with particular emphasis on locating the neuromuscular junctions. Sections of interest were freed from the plastic sandwich and remounted for further $1 \mu \mathrm{m}$ and ultrathin sectioning.

\section{Results}

\section{LIGHT MICROSCOPY}

Scattered among the predominantly normal-appearing fibres were cells in varying stages of degeneration (Fig. 3). Many fibres were enlarged and hyalinised. These and other cells frequently contained vacuolated regions and showed loss of myofibrillar organisation. Inflammatory infiltrates and lymphocytic collections were not observed.

\section{ELECTRON MICROSCOPY}

The hyalinised fibres typically contained large clusters of mitochondria and showed loss of myofibrillar organisation (Fig. 4). The mitochondria in such clusters often appeared swollen, disrupted, and vacuolated; their cristae showed fragmentation.

Other fibres showed varying degrees of vacuolar aggregations. Such vacuoles most probably represented swollen sarcoplasmic reticulum and/or resulted from mitochondrial breakdown. In Fig. 5 a vacuolar aggregate is seen in a muscle fibre showing minor myofibrillar disruption. In an advanced stage of cellular degeneration the vacuolar aggregates become increased in amount and there is loss of myofibrillar organisation (Fig. 6). Quite often, necrotic myofibrils were fused into an amorphous mass, which form electron-dense serpentine strands.

Various nuclear abnormalities were seen. They included highly involuted configurations, often with various pseudoinclusions (Fig. 7), as well as pyknotic nuclei.

Subsarcolemmal inclusions were frequently observed. One type was composed of finely granular, particulate matter, which formed regular clustering about foci which tend to be spaced at approximately 1200-1400 \& (Fig. 8). Their electron density varied from light (Fig. 8) to moderate (Fig. 9). A second type of inclusion appears to be a Hirano body (Fig. 10).

Neuromuscular junctions were seen on apparently normal and disrupted fibres. In some cases the axonal terminals appeared highly pyknotic (Fig. 11). These axonal terminals occasionally showed some loss of their axolemma.

The intramuscular nerves at times showed alterations. In many cases such nerve twigs contained 


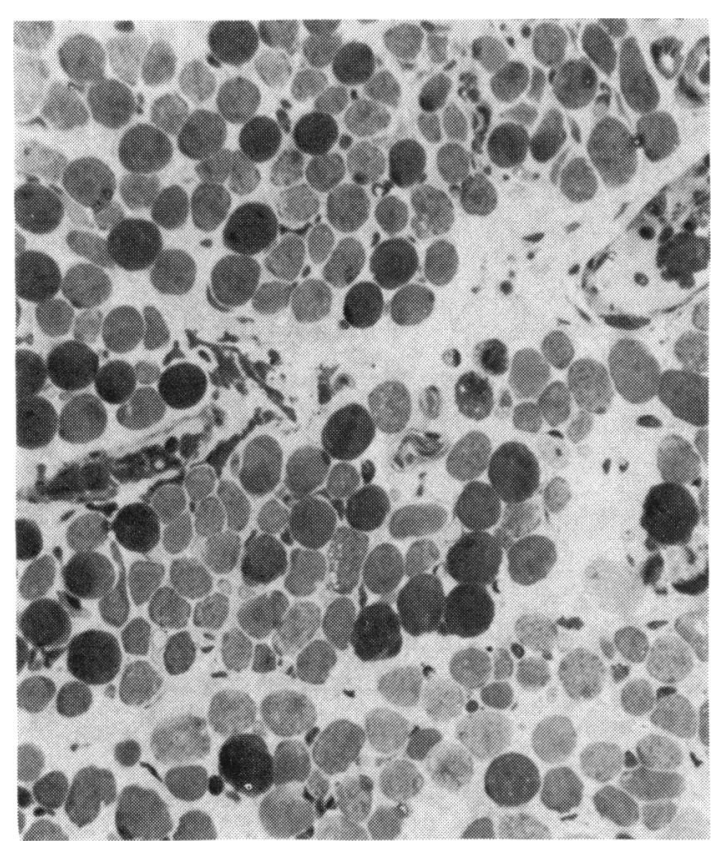

Fig. 3 Inferior oblique muscle. Hyalinised, vacuolated, and necrotic fibres are seen (methylene blue, $\times 260$ )

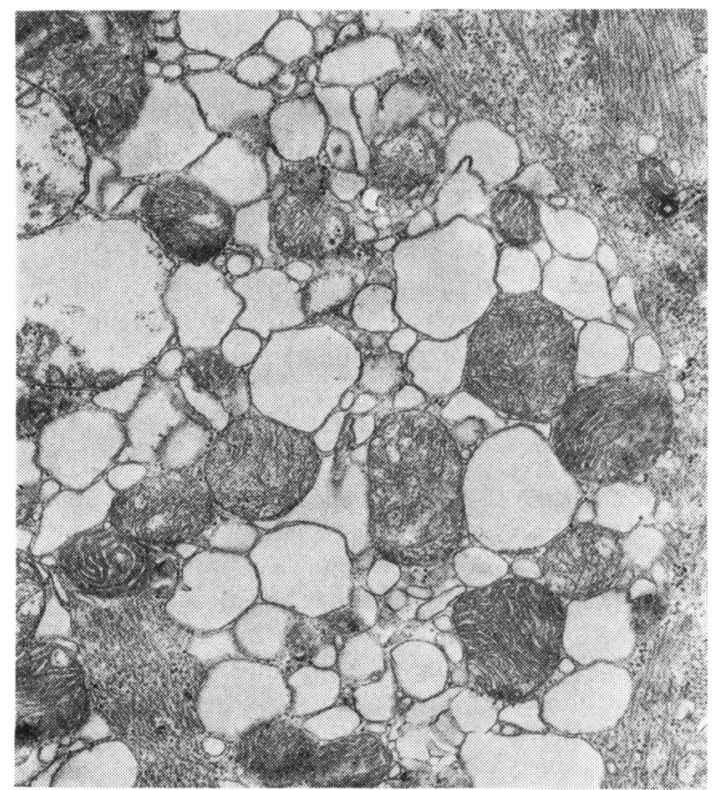

Fig. 5 A large vacuolar aggregate, consisting presumably of dilated sarcoplasmic reticulum components and mitochondria which have degenerated $(\times 15000)$

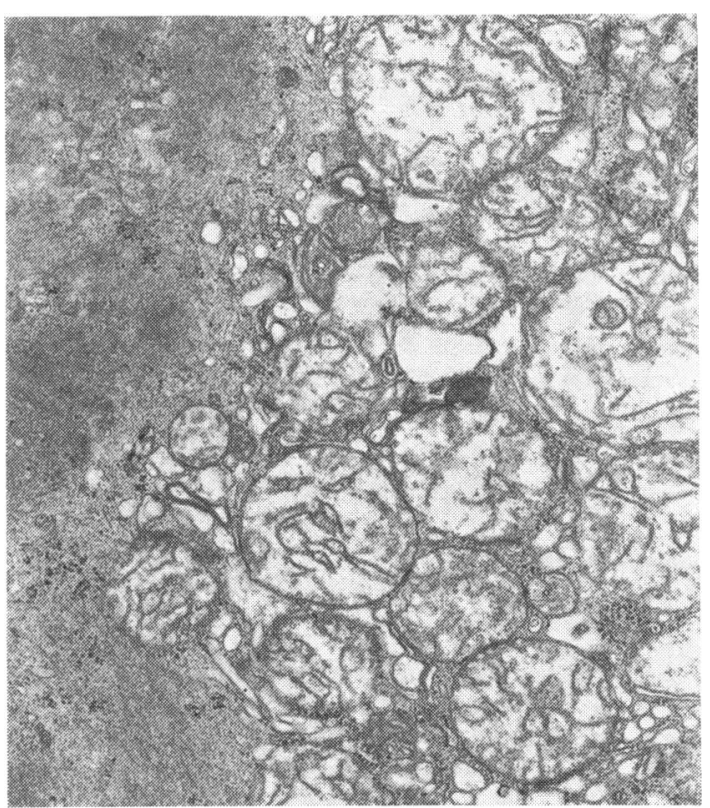

Fig. 4 Marked clustering of mitrochondria, which are in various stages of disruption. The myofibrillar organisation is indistinct $(\times 15000)$

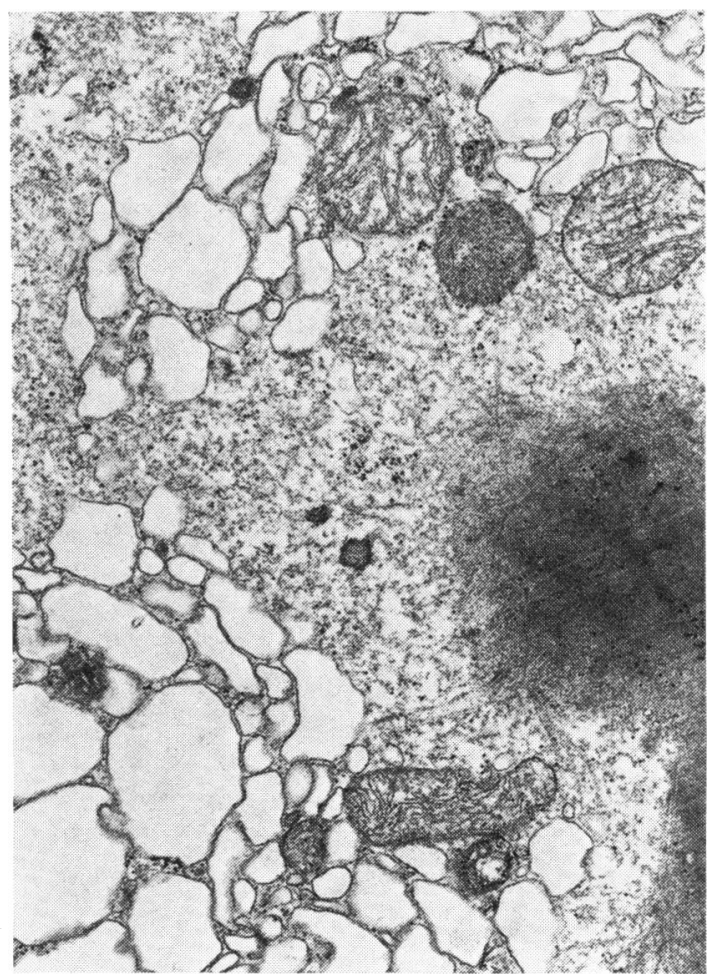

Fig. 6 Necrotic fibre with vacuolar aggregates and loss of myofibrillar material $(\times 15000)$ 


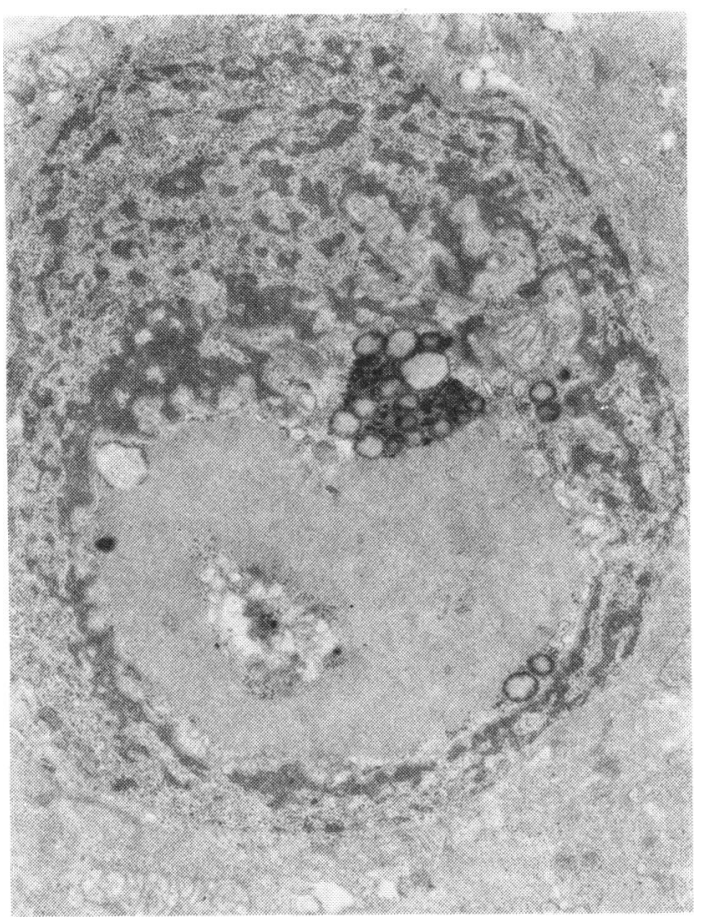

Fig. 7 A large nuclear pseudoinclusion containing an inclusion body and lipofuscin material $(\times 11000)$

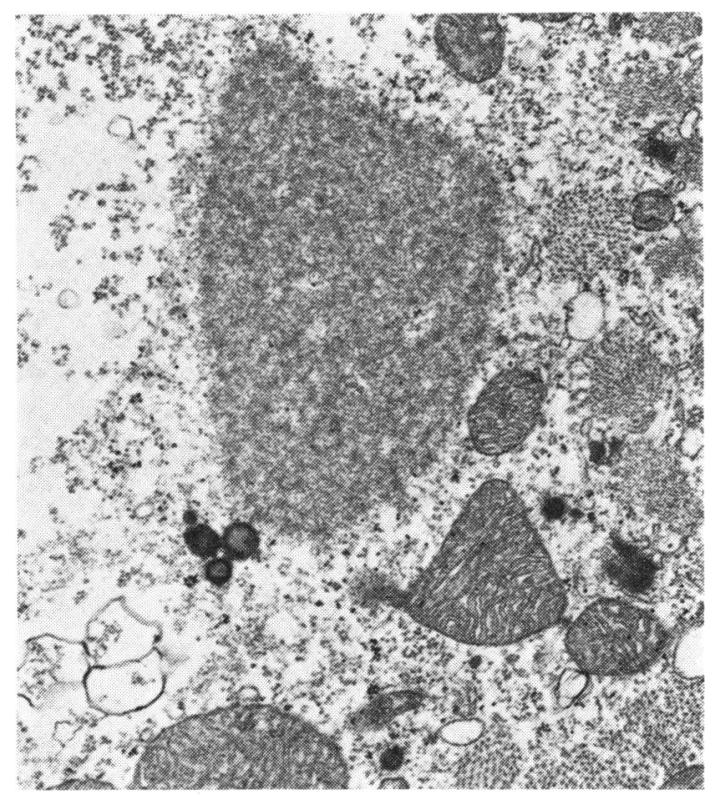

Fig. 9 Subsarcolemmal inclusion body, non-membrane bound, and moderate electron density in a disrupted muscle fibre $(\times 15000)$

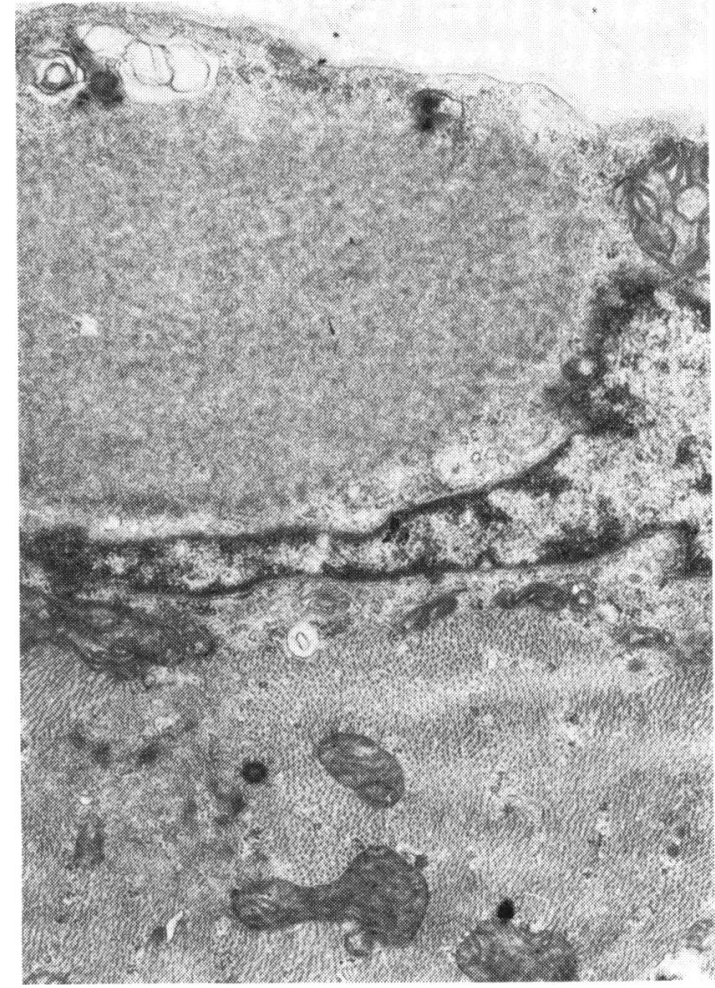

Fig. 8 Subsarcolemmal inclusion body, non-membrane bound, composed of finely granular particulate material in an apparently normal muscle fibre $(\times 15000)$

laminated structures (Luse bodies) characterised by a definite periodicity. Such structures appeared to arise from or to be in close association with the basement membrane of the Schwann cell (Fig. 12). Schwann cell inclusions were also seen (Fig. 13). These appeared similar to the $\pi$ granule of Reich. The axons within the nerve twigs occasionally showed significant myelin degeneration (Fig. 14).

\section{Discussion}

The high frequency of various alterations in muscle cell structure observed here strongly suggests a pathological state.

In the present study mitochondrial aggregates were observed in the fibres of both the orbital and the global regions. In a recent study of overacting inferior oblique from patients with various types of strabismus by Mukuno et al. (1976) myopathic alterations were observed, prominent among which were central cores of closely packed aggregates of mitochondria. These were mostly seen in smalldiameter fibres on the orbital surface and were rare 


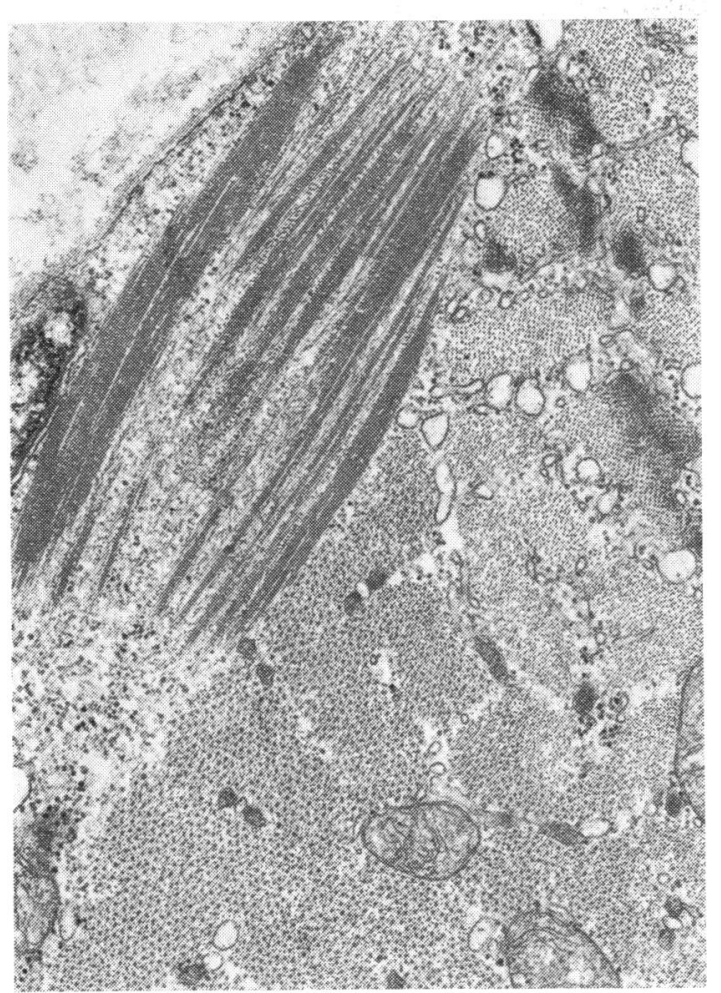

Fig. 10 A subsarcolemmal Hirano body inclusion $(\times 21000)$

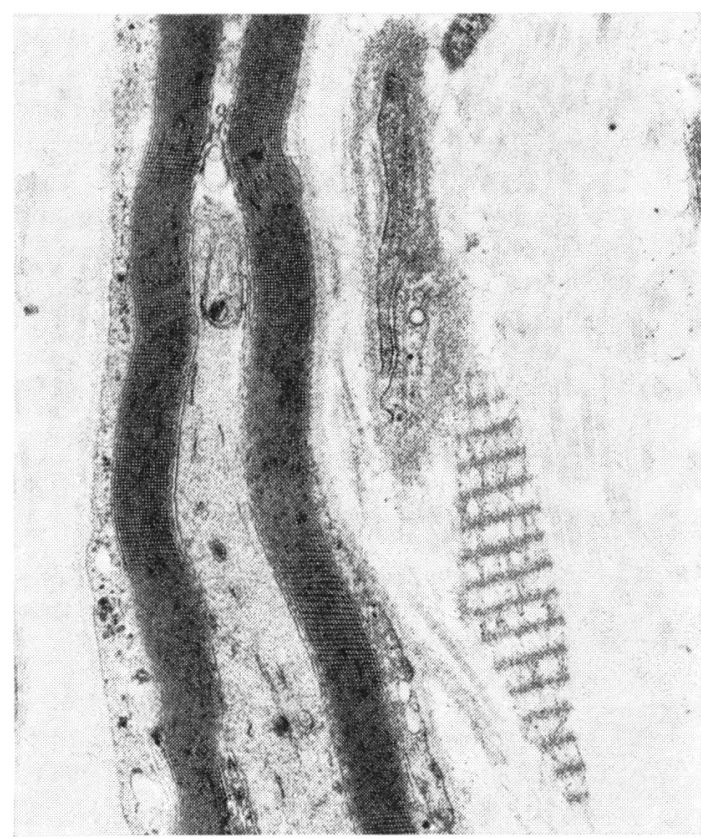

Fig. 12 Intramuscular nerve showing a Luse body (elongated laminated structure) apparently attached to the basement membrane of the Schwann cell $(\times 21000)$

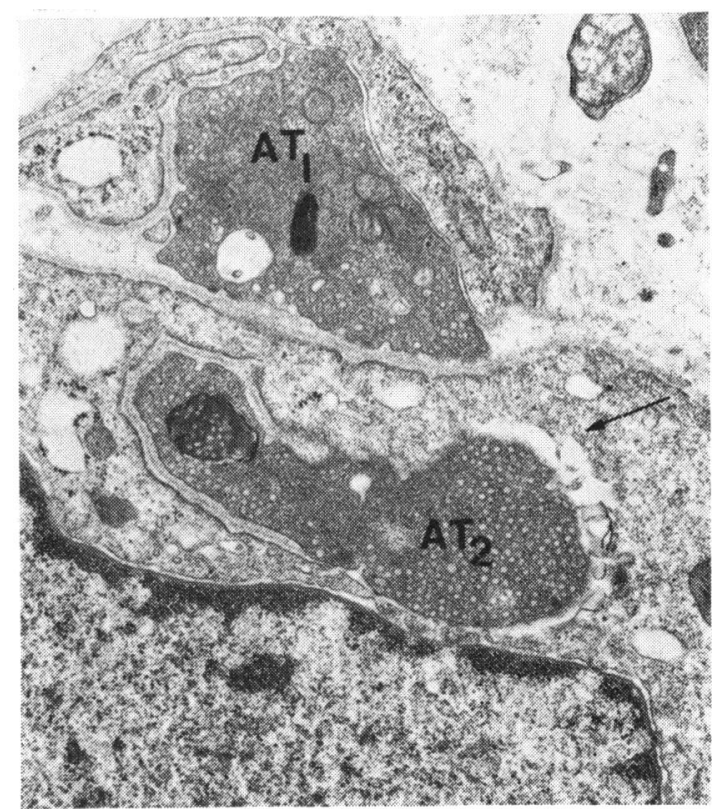

Fig. 11 Motor endplate showing two axonal terminals $\left(A T_{1}\right.$ and $\left.A T_{2}\right)$ which appear pyknotic. One axonal terminal $\left(A T_{2}\right)$ shows a focal loss of its axolemma; the subjunctional region shows some degeneration (arrow) $(\times 15000)$

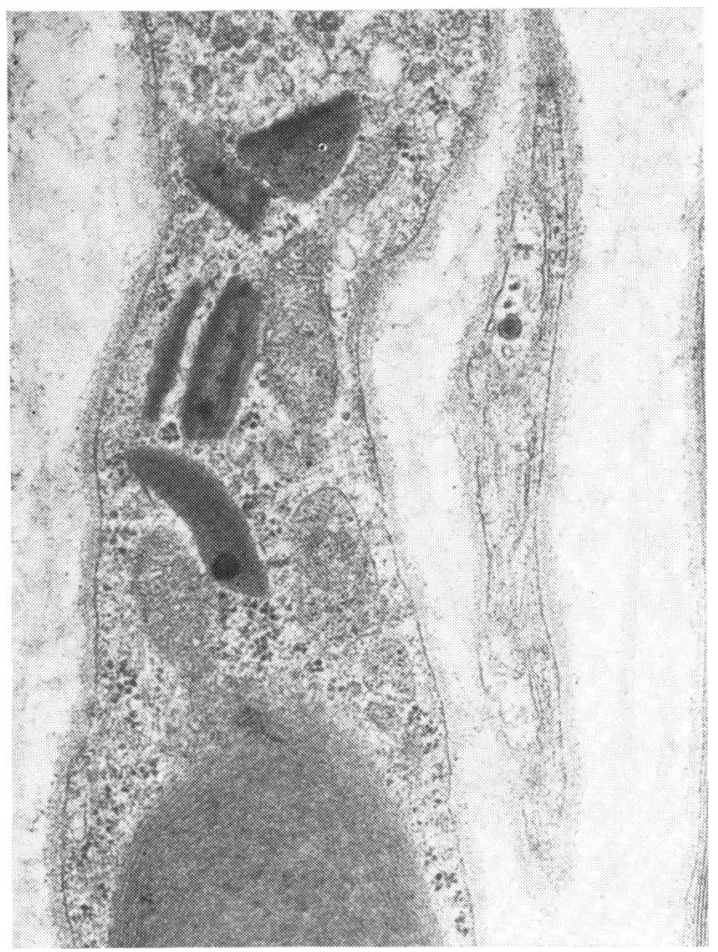

Fig. 13 Intramuscular nerve, the Schwann cell of which contains several inclusion bodies $(\times 27000)$ 


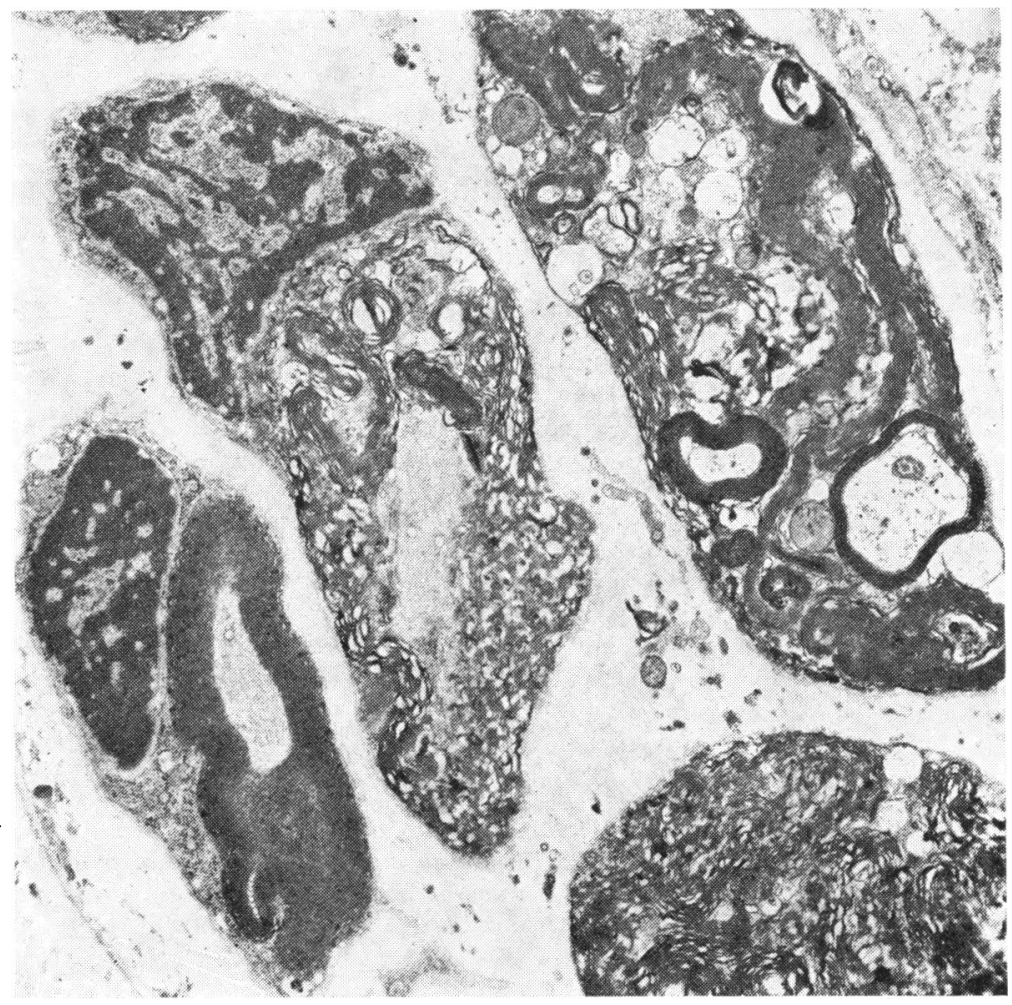

Fig. 14 Intramuscular nerve showing myelin degeneration $(\times 13000)$

in the global region. Mitochondrial abnormalities, such as aggregation, distension, vacuolation, and fragmentation, have been described in both myopathic and neurogenic diseases with altered ocular movements (Sakimoto, 1970; Adachi et al., 1973).

Subsarcolemmal inclusions of finely granular structures and Hirano bodies were frequently observed in this study. Comparable granular structures have been previously described in extraocular muscle from patients with myotonic dystrophy (Culebras and Merk, 1975), from ageing individuals (Miller, 1975), as well as other neuromuscular disorders (Mair and Tome, 1972). Hirano bodies have been seen in myasthenic extraocular muscle (Sakimoto, 1968) and in a clinically overacting inferior oblique from a patient with exotropia (Martinez and McNeer, 1976). They also occur in cortical neurons showing neurofibrillary degeneration and granulovacuolar bodies in patients with Guam amyotrophic lateral sclerosis-parkinsonism-dementia complex (Hirano, 1965).

Alterations of the neural apparatus were less prominent. These included occasional disruption of neuromuscular junctions, axonal degeneration, and the presence of Luse bodies, and Schwann cell inclusions which were similar to the $\pi$ granules of
Reich. Luse bodies have been reported in pathologic extraocular muscle (Martinez and McNeer, 1976), as well as in neurogenic tumours (Friedmann et al., 1965). The $\pi$ granules of Reich have been described in nerves of patients with various neuromuscular disorders (Evans et al., 1965) and in nerves from patients with hypothyroid neuropathy (Dyck and Lambert, 1970).

It thus seems likely that, at least in this case of Apert's syndrome, the motility disturbance may in part be related to abnormality of the extraocular muscles themselves rather than be due to mechanical factors alone.

The authors acknowledge the skilful technical assistance of Miss Barbara Zimmer.

This study has been supported by National Institutes of Health Grant EY-00309 from the National Eye Institute.

\section{References}

Adachi, M., Torii, J., Vold, B. W., Briet, P., Wolintz, A., and Schneck, L. (1973). Electron microscopic and enzyme histochemical studies of cerebellum, ocular and skeletal muscles in chronic progressive ophthalmoplegia with cerebellar ataxia. Acta neuropathologica, 23, 300. 
Apert, E. (1906). De l'acrocephalosyndactylie. Bulletin et Mémoires de la Société de Médecine de Paris, 23, 1310.

Culebras, A., and Merk, F. B. (1975). Cytoplasmic inclusion bodies in superior rectus muscle of the eye. Neurology (Minneapolis.), 25, 422.

Davidowitz, J., Pachter, B. R., and Breinin, G. M. (1976). 'Clearing' steel knife Epon sections in a polystyrene film sandwich. Stain Technology, 51, 139.

Davis, F. A. (1925). Tower skull, oxycephalus. American Journal of Ophthalmology, 8, 513.

Dyck, P. J., and Lambert, E. H. (1970). Polyneuropathy associated with hypothyroidism. Journal of Neuropathology and Experimental Neurology, 29, 631.

Evans, M. J., Finean, J. B., and Woolf, A. L. (1965). Ultrastructural studies of human cutaneous nerve with special reference to lamellated cell inclusions and vacuole-containing cells. Journal of Clinical Pathology, 18, 188.

Friedmann, I., Cawthorne, T., and Bird, E. S. (1965). Broadbanded striated bodies in the sensory epithelium of the human macula and in neurinoma. Nature, 207, 171.

Hirano, A. (1965). Pathology of amyotrophic lateral sclerosis. In Gajdusek, D. C., and Gibbs, C. L. (eds.), Slow Latent and Temperate Virus Infections, NINDB monograph No. 2, p. 23. National Institutes of Health: Bethesda.

Laitinen, L., Miettinen, P., and Sulamaa, M. (1956). Ophthalmological observations in craniosynostosis. Acta Ophthalmologica, 34, 121.
Lloyd, L. A. (1975). Craniofacial reconstruction: Ocular management of orbital hypertelorism. Transactions of the American Ophthalmological Society, 73, 123.

Mair, W. G. P., and Tome, F. M. S. (1972). Atlas of the Ultrastructure of Diseased Human Muscle. ChurchillLivingstone: Edinburgh.

Martinez, A. J., and McNeer, K. W. (1976). Extraocular muscles. Light microscopy and ultrastructural features. Acta neuropathologica, 34, 237.

Miller, J. E. (1975). Ageing changes in extraocular muscle. In Lennerstrand, G., and Bach-y-Rita, P. (eds.), Basic Mechanism of Ocular Motility and their Clinical Implications, p. 47. Pergamon Press: Oxford.

Miller, M., and Folk, E. (1975). Strabismus associated with craniofacial anomalies. American Orthoptic Journal, 25, 27.

Mukono, K., Ishikawa, S., Togo, T., and Minei, Y. (1976). Histopathological study on the overacted inferior oblique muscles with special reference to 'central core' within the muscle fibers. Japanese Journal of Ophthalmology, $20,166$.

Sakimoto, T. (1968). Electron microscopic studies on human ocular muscles. (1) Filamentous and membranous structures in the extraocular muscle fibres. Acta Societatis Ophthalmologica Japonicae, 72, 175.

Sakimoto, T. (1970). Fine structure of extraocular muscle with myasthenia gravis. Japanese Journal of Ophthalmology, 14, 60 . 